\title{
Why Agonists Should Stop Discussing With Deliberative Theorists
}

\author{
Ásgeir Tryggvason
}

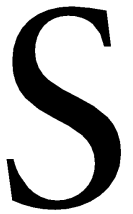

ome discussions carry the embryo of genuine and mutual understanding, while others do not. In educational research there has been an ongoing discussion between agonists and deliberative theorists about democratic education; one that I have been engaged in on "the agonistic side" of the fence. This discussion has revolved around normative questions, such as: What role should emotions and identities have in classroom discussions, and what should the aim of the classroom discussions be? Deliberative theorists have argued that teachers should focus on the rational argument - the issue itself - and try to leave emotions and identities on the sidelines. Deliberative theorists argue that a key aim for discussions is that they should aim towards a consensus on political issues (Englund, 2016; Samuelsson, 2018). Agonists, on the other hand, have emphasised that emotions and identities are unavoidably intertwined with political issues and conflicts. Wanting something to be changed in society, such as the end of police brutality, cannot be detached from the affective investment of wanting. Agonists argue that a commitment to democracy, equality and justice cannot be detached from the emotional aspect that comes with it (Tryggvason, 2017).

From my agonistic standpoint, these discussions have been defensive and non-productive for agonistic theory development. When presenting papers at conferences on agonism, a common question from the audience is: "Why do you need to separate agonism from deliberative theory - why don't you try to combine them instead?" Questions like these are kind, genuine and explorative, but this ongoing discussion about the relation to 
deliberation does something to agonistic thought and theory development in educational research. A lot of time is spent explaining agonism and how it differs from deliberative theory. For agonists, this has primarily been a pedagogical rather than a theoretical task. It seems as though agonistic theory development in educational research is on the losing end of this stalemate situation with deliberative theorists.

The aim of this essay is to open up a discussion about theory development in agonistic educational research. In order to directly address the unproductiveness of the agonism-deliberation discussion, this essay turns inwards toward the richness and diversity of agonistic thought. As I see it, there are two reasons why agonists should stop discussing with deliberative theorists. The first, is that the discussion is unproductive and at a stalemate, both of which hamper agonistic theory development. The second reason is that agonists do not need the discussion with deliberative theorists to develop agonistic theory in educational research.

One explanation as to why the discussion is at a stalemate is perhaps due to the ontological differences undergirding agonism and deliberative theory. As I have outlined elsewhere, agonism and particularly Mouffe's agonistic theory - is based on an ontological understanding that is incompatible with deliberative theory (Tryggvason, 2018a, 2019). Thus, in a strict sense, agonists and deliberative theorists do not disagree about the roles that emotions and identities should have in education because they have fundamentally different understandings of what emotions and identities are in the first place, and how they relate to political life. Withdrawing from such a discussion is therefore not about stopping talking to or with someone who disagrees with you. It is rather about leaving a discussion with someone who is talking about a completely different issue than you are.

When we as agonists in educational research are too busy pushing back against the dominant consensus-oriented theories, there is little energy left for a theory development of our own. The rich history of agonism, which has been thoroughly explored in political science, is seldom present in educational research. This is hardly 
surprising, given that agonism, and specifically Mouffe's (2005) agonistic theory, has historically been developed in relation to deliberative theory. Thus, when these theoretical positions are transposed into educational research, a discussion between them follows (Englund, 2016; Leiviskä \& Pyy, 2020; Samuelsson, 2018; Tryggvason, 2018a; Zembylas, 2018). But the rich and diverse history of agonistic theory has also been developed apart from deliberative theory. This history consists of a palette of agonistic ideas, concepts and traditions that in turn stem from disparate theoretical sources. Honig (1993) draws on Arendt, while Arendt draws on the ancient Greeks. Connolly (1993) is inspired by Nietzsche, while Mouffe (1999a) draws on Carl Schmitt in an attempt to "use Schmitt against Schmitt" (Mouffe, 1999a; p. 52; see also Glover, 2012; Schaap, 2007; Tryggvason, 2018b).

The richness and diversity of this heritage has not yet been included in educational research (Koutsouris et al., 2021). Instead, agonists in educational research tend to pick one agonistic line of thought and stick to it. Most of us pick Mouffe, while others pick Arendt (ibid.). But any fruitful and vivid discussion between them is hard to find in educational research. ${ }^{1}$

Against this background, the essay is intended as a call to other agonists in educational research that it is time to attend our own theoretical tradition and leave the stalemate discussion with deliberative theorists behind. I will try to initiate this internal discussion by exploring and elaborating on how agonistic theory has conceptualised the Other. The ambition is to draw on the richness of agonistic thought and highlight how agonistic theory itself is a sufficient and fertile theoretical ground for educational research.

\footnotetext{
${ }^{1}$ An exception here is the work of Carsten Ljunggren, who already in I996 elaborated on a radical democratic conception of democratic education by drawing on the tensions between different agonistic traditions (see Ljunggren, I996, 2007). Another exception is the work of Lovisa Bergdahl (20 I0).
} 
But the idea of agonistic theory is not meaningful without a constitutive "outside", just as our identity as "agonists" is not a meaningful subject position in educational research without the Other. Thus, our identity as "agonists" cannot function as a meaningful subject position in educational research without the Other. In acknowledging this, I will use deliberative theory as our constitutive outside. This is not an attempt to engage in a discussion with deliberative theorists, which would be contradictory to the aim of this essay. Rather, it is an attempt to methodologically use deliberative theory as an otherness that can deepen and develop the internal discussion about agonistic theory in educational research.

In the following sections I outline two conceptualisations of the Other that have affected the agonistic project in different ways. The first is the deliberative idea of inter-subjectivity (see Erman, 2009) and the second is the intra-subjectivity found in the work of Carl Schmitt (1932/2007). Against the background of these two conceptualisations, I elaborate on how agonistic theory, and particularly the work of Arendt, moves to an understanding in which the Other is the immediate and contingent relation between otherness and our own signification (Ljunggren, 1999a). I argue that this agonistic understanding of the Other is not only qualitatively distinct from the deliberative notion of the Other, but more importantly, is absolutely distinct from the deliberative theorists' projection of what agonism is.

\section{"Halt! Who goes there?"}

In her article What is wrong with agonistic pluralism? the political theorist Erman (2009) criticises Mouffe's agonistic theory from the vantage point of deliberative theory. Without going into this particular debate, I want to highlight some of Erman's critical questions because they clearly illustrate how the inter-subjective conception of the Other undergirds deliberative theory. For Erman, a main problem with agonistic theory is the idea of antagonism. The problem is that the agonistic theory cannot explain how someone can identify the Other as an antagonist if they do not share a 
common symbolic space (Erman, 2009). Erman focuses on the preconditions for antagonism and enmity within Mouffe's agonistic theory. Mouffe $(1999 \mathrm{~b}, 2000)$ defines antagonism as relations between identities that do not share a common symbolic space. In my reading of Erman, I understand her question to be this: How can I recognise someone as my enemy if we do not share a common symbolic space? From Erman's perspective, it would be impossible to distinguish the friend from the foe if there was no shared symbolic space. In other words, there has to be some kind of common understanding between me and my enemy in order for us to have an antagonistic relation. Erman writes:

\footnotetext{
The distinction between subject and object (and between particular and general) can only be meaningfully understood within an available conceptual and thus symbolic space, which presupposes a common understanding. This means that the actors involved can only identify an antagonistic conflict as such through some common presumptions about each other as subjects. Unfortunately, following Schmitt, Mouffe would never attribute to antagonism such a dimension of common understanding, since the point with the distinction between friend and enemy is precisely that there is no common understanding at all. (Erman, 2009, pp. 1046-1047)
}

At first glance, Erman's argument seems problematic for Mouffe's agonistic theory. However, what is not made explicit in this line of reasoning is that the argument is based on a static understanding of the relation between subjects, i.e., inter-subjectivity. In this idea of inter-subjectivity, the Other is seen a stable object that exists prior to and independent of our encounter. The inter-subjectivity is in this sense an encounter between two stable entities: us and them, subject and object.

From an agonistic perspective, Ljunggren (1999a) has criticised this static notion of identity and inter-subjectivity and pointed to how this notion is related to an idea of cultures as fixed entities:

Only if you allow yourself to locate the Other as something possible to refer to as an object, an historically permanent one and something separated from yourself as a subject, only then do diversity and difference make sense as a basis for understanding culture and identities as fixed entities. (Ljunggren, 1999a, p. 53) 
In his critique of this idea of stable inter-subjectivity, Ljunggren highlights how it turns the question of the Other into a question of knowledge: "Cultural diversity signifies that in the society there (a) are diverse cultural positions which (b) can be located (c) by $u s^{\prime \prime}$ (Ljunggren, 1999a, p. 49, emphasis in original). The idea of stable inter-subjectivity is therefore an idea in which the identities of both "us" and "them" are already fixed prior to every encounter. From such a perspective, the main question always becomes: what is the Other? (Ljunggren, 1999b).

A similar critique of the inter-subjective perspective can be found in the work of Honig (1993). Honig points to how the idea of the Other's stable identity becomes an inquiry into whether the Other is one of "us" or not. It is in answering this question that the Other becomes exclusively a question of knowledge. Honig's argument becomes clear in her critique of the communitarian theory represented by Sandel. Honig writes: "For Sandel, the problem posed by the other is a problem of knowledge or recognition: can "we' discern traces of ourselves in the other?" (Honig, 1993, p. 12; cf. Glover, 2012; Ljunggren, 2010). As we know, this search for knowledge is not curious and innocent, but a search for knowledge that can be used to establish order and define stable boundaries between "us" and "them". As Honig (1993) formulates it, it is a "need to fit unruly others into neat categories of sameness and difference, friendship and enmity 'Halt! Who goes there?"' (p. 12, emphasis in original). What we are seeing here is a stable intersubjectivity that undergirds both the deliberative and the communitarian understanding of the Other.

Before I elaborate on the agonistic understanding of the Other, the intra-subjective perspective needs to be discerned, as it plays a crucial role for agonistic thought. Let us turn to Carl Schmitt.

\section{Halt! Who are we?}

If the deliberative and communitarian theories promote a particular form of inter-subjectivity, then we find Carl Schmitt at the other end of the spectrum representing a radical intra- 
subjectivity. We could say that when the inter-subjective perspective thrives for knowledge about the Other, the intrasubjective perspective instead pursues knowledge about "us". Thus, instead of asking the inter-subjective question "what is the Other?" the intra-subjective questioning turns inwards to: "who are we"? This idea becomes evident when Schmitt describes how to recognise the enemy. We could say that the question that Erman posed in 2009 (about how to recognise the antagonist/enemy) was answered by Schmitt in 1932:

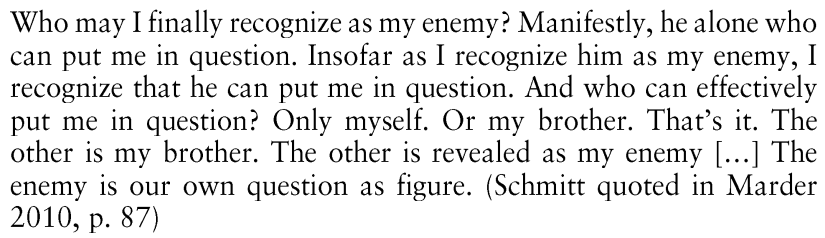

What Schmitt does here is to locate the enemy as one's own question as figure. The enemy, or the antagonistic Other, is not located as a concrete Other but as the figure who "puts me in question". How can we then locate this figure? As Schmitt writes, the figure is our own question. Here we see the contours of what could be described as a radical intra-subjectivity. The enemy, as Schmitt sees it, stems from my own questioning, where the Other is always a question about who "we" are.

This radical intra-subjectivity is grounded in the observation that the Other does not have to exist in order for "us" to exist. ${ }^{2}$ It would be excessive to demand that every collective formation of an "us" is dependent on a concrete existence of the Other. For Schmitt, this is why "humanity" cannot be a political entity, "because it has no enemy, at least not on this planet" (Schmitt, 1932/2007, p. 54). What is needed, however, is a figure that can function as the Other. For instance, for a group of neo-Nazis to become a collective identity they need a figure of the Other. Whether the Other exists or not is not a necessity. What is important is the signification and articulation of the Other as a figure that puts them into question

${ }^{2}$ For a critical reading of Schmitt in this issue, see Abizadeh (2005). 
(Marder, 2010; cf. Laclau, 2007). In the case of neo-Nazis, their main figure, the Zionist Occupation Government, is non-existent yet still functions as the Other that constitutes them as a collective identity. $^{3}$

Returning to Schmitt, his notion of intra-subjectivity can be seen as an anti-thesis to the inter-subjectivity that is put forward by deliberative (liberal) and communitarian theories. From an intrasubjective perspective, the search for knowledge is always a search that turns inwards: Halt! Who are we?

\section{Agonistic otherness}

Let us now turn to the main issue of this essay, namely the agonistic understanding of the Other. In short, we could say that agonism dwells in the interplay between inter- and intra-subjectivity, and it is against the background of the two passages above that the contours and specificity of agonism can be outlined.

First of all, agonism is not a theory that combines inter-subjectivity and intra-subjectivity. In that sense, it is not a theory that combines two parts but is a synthetisation that qualitatively differs from inter- and intra-subjectivity. What is in focus is therefore not "what is the Other?" and "who are we?", but the relation that emerges between these subjectivities. In order outline how agonism is the interplay between inter and intra, I will start with Arendt's (1958) conceptualisation of the public sphere and, more precisely, in the discussion about what threatens the public sphere. It is in this discussion that we find the keys to understand the agonistic conceptualisation of the Other.

\footnotetext{
${ }^{3}$ Here it is important to highlight that the violence and hate of neo-Nazis is directed toward concrete persons and organisations, even if the neoNazis' figure is not concrete.
} 
What threatens the public sphere?

According to Arendt (1958), the constitution of a "we" takes place through its own manifestation. In this sense, a "we" is constituted in and by its own action - there is no doer behind the action and there is no "we" that exists prior to the constituting act itself. Such an act, as Arendt reminds us, is always an act in the public sphere, and in a stronger sense, it is only in the public sphere that it is possible to act (Bergdahl, 2010). A clear example of this is found in the American Constitution and the performative act in declaring "We, the people". From Arendt's perspective, this "we" is born into the world in the act of declaring itself in a public sphere (Arendt, 1958).

This way of conceptualising the relation between actions and the public sphere has certain consequences. If the public sphere is threatened, or loses its role in society, it follows that the possibility to act will also be threatened. What Arendt highlights is that the private sphere has a tendency to occupy the public sphere with the consequence that our ability to act is weakened. This understanding stems from Arendt's distinction between the private and the public, and the distinction between the social and the public. For Arendt, there is a qualitative distinction between social issues and public issues, where social issues are nothing but the aggregation of issues belonging to the private sphere. In other words, a social issue is the aggregation of private issues. When the private sphere occupies the public sphere, it does so in terms of social issues. Thus, private issues become aggregated into social issues and push what is truly public out of the public sphere (Pitkin, 1998). But how should this threat to the public sphere be understood - who is threatening it?

Honig (1993) presents two ways of interpreting Arendt on this point. The first interpretation is as a threat coming from a particular group of people. It could be a social group in society that threatens the public sphere from within, such as a social class. It could also be a group that does not belong to society but threatens it from the outside, i.e., "the barbarians". As I see it, this way of 
formulating the threat as coming from a particular group is an inter-subjective understanding of the threat.

The second interpretation of what threatens the public sphere is the intra-subjective understanding of the Other. This means that the threat should not be "identified with particular classes of people, or bodies, or women in particular. But as 'particular attitude[s] against which the public realm must be guarded"' (Honig, 1993, p. 82, citing Pitkin, 1998, emphasis in original). Specifically, it is the attitudes that the private realm brings with it (through work and labour) that threaten the public sphere. From this intra-subjective position, the threat should not be understood as something that resides outside the public sphere itself, but as something that comes from within. It is when the public sphere takes on the attitudes from work and labour, rather than actions, that it loses its self-understanding as a public sphere (cf. Dewey, 1927). It is in this loss of self-understanding that it becomes a sphere for social issues and not a realm for action.

What this agonistic understanding of the public sphere teaches us is that there must be a public sphere in order to act, and that it is by acting in this public sphere that a "we" can constitute itself. This should not be misunderstood. Even when the people declare itself as "we, the people" in a public sphere, it is never an allencompassing intra-subjectivity because such an act is constituted by contingency.

\section{Contingent subjectivity}

To further elaborate on the agonistic conception of subjectivity as contingent, I will use the communitarian perspective as a steppingstone. From a communitarian perspective, the constitution of my own identity depends on the community to which I belong. To be who I am is never a solo act but is always dependent on the community (Sandel, 2006; see also Honig, 1993). This means that I am in debt to my community for the constitution of my own identity. But, as Honig asks, why should we believe that our debt stops at the community borders? If the constitution of "us" is 
established by "the others who we are not" - this would mean that "we" are in debt to "them" as well. Honig writes:

After all, figures who frighten and repel us play a part in our constitution as a "we", a "we" that is what it is (partly) insofar as it is not "them". Blackness plays a part in the constitution of whiteness, masculinity in femininity, master in slave, terrorist in state, and overman in herd. Perhaps the logic of indebtedness extends across the line of opposition that marks each of these pairs. (1993, p. 171)

From Honig's agonistic perspective, the Other is the one who disrupts the lines between friend and enemy by resisting the binary categorisation. In this, the Other is the one who also disrupts "us" as a stable identity with fixed borders. At the same time, the Other is the one who "we" are in debt to for constituting "us". As Honig (1993) puts it: "The other disrupts. And for this the virtú theorist is indebted to the other, the enemy who is also a friend" (p. 194, emphasis in original). What we have here is neither a stable intersubjectivity nor an intra-subjectivity, but rather a theory that underlines the contingent interplay between subject and object.

How, then, should the interplay itself be understood? Here, Ljunggren's (1999a) concept of identity/difference can help us to specify the interplay between inter and intra. This concept highlights how the constitution of "us" and "them" is an inseparable process of inter-subjective and intra-subjective action.

[...] culture and identity must be understood as a contingent process of becoming where the identity is signified in confrontation with heterogeneous others - and with a heterogeneous self. This is to say that there is no essentialism in a given culture or cultural identity. This, in turn, means that cultures are constituted only in relation to that otherness internal to their own signifying and (symbol-forming) communicating processes which make 'culture' decentred structures... (Ljunggren, 1999a, pp. 53-54, emphasis added)

It is important to highlight that it is not identity and difference, which would be an inter-subjective understanding based on stable identity and stable difference. Instead, what we have is identity/difference as a compound concept, where identity and difference are already interwoven and constitutive of each other 
(cf. Bergdahl, 2010). Thus, the constitution of a "we" is a dual process that is about a confrontation with others and about the internal signification. The confrontation with the Other, as Ljunggren (1999a) highlights, is not one between two stable and pre-fixed identities but is rather a confrontation where both "we" and the Other are heterogenous (cf. Laclau \& Mouffe, 2001, p. 125).

From this perspective, a collective identity is a question of a relation between otherness and internal signification. What matters is therefore not only the Other, or only the internal signification, but the relation between otherness and the internal signification. By seeing the interplay in terms of identity/difference points us to how agonism is a true synthetisation of inter and intra that qualitatively differs from simple combination. What is important to keep in mind is that this interplay is always characterised by its contingency (Ljunggren, 1999a). The contingency that undergirds the relation between inter and intra is not a temporary uncertainty, or pure chance, but is rather an ontological contingency that stems from communication itself as being contingent. Recognising the Other is in this sense not an epistemic endeavour, but a process of re-thinking and re-cognising oneself and the Other in contingent encounters (Ljunggren, 2010; Bergdahl, 2010).

\section{Two answers}

Let me return to the initial question posed by Erman (2009): "[H]ow is it possible for antagonism proper to be a conflict between us and them (or me and the Other) without any 'common symbolic space', to use Mouffe's words?" (p. 1046). What Erman presupposes is that this common symbolic space exists before the very confrontation between "us" and "them". What agonistic theory points to is that this space should be understood as a communicative realm that comes into existence in the very moment of action (Arendt, 1958, p. 199). As Arendt formulates it: "the organization of a people as it arises out of acting and speaking together, and its true space lies between people living together for 
this purpose, no matter where they happen to be" (Arendt, 1958, p. 198, my emphasis).

With this way of formulating the public sphere we now have two different answers to Erman's question. The first answer, which I described above, can be found in Schmitt's idea of the Other as "our own question as figure". The second way of answering the question is to follow Arendt and point to how the question itself rests on a problematic understanding of both the public sphere and the Other. In this way, agonism does not only provide us with an answer, but also opens up for a different way of re-thinking the relation between "us" and "them" as well as the public sphere (Bergdahl, 2010).

\section{Two conclusions}

This essay starts out with the aim of initiating a discussion about agonistic theory development in educational research by elaborating on the agonistic notion of the Other. With deliberative theory as a backdrop, the essay outlines how agonism conceptualises the Other in terms of a contingent interplay between inter- and intra-subjectivity. As shown above, this interplay can be understood as identity/difference, where identity and difference are always already intertwined with each other.

Given this agonistic understanding of the Other, we could ask what this means when it comes to antagonism and enmity. As I see it, two important points need to be highlighted. First, by seeing the constitution of "us" and "them" as a contingent interplay between inter-subjectivity and intra-subjectivity, it follows that every transformation of this boundary must involve both intersubjectivity and intra-subjectivity. Second, a crucial implication is then that every attempt to transform enemies into adversaries needs to be understood as a process that is both about "us" and about "them". More specifically, it needs to be understood as a transformation of an otherness that is internal to our own signification, "where the identity is signified in confrontation with 
heterogeneous others - and with a heterogeneous self" (Ljunggren, 1999a, p. 53).

The agonistic conceptualisation of the Other provides us with theoretical tools and ways of thinking that we do not get from the ongoing discussion with deliberative theorists. By making use of the richness and diversity that agonistic theory offers, it becomes possible to unfold a more nuanced and multi-layered understanding of key concepts within agonistic theory, such as antagonists and adversaries. This unfolding becomes possible if we attend to the theoretical tasks that need to be dealt with in agonistic theory and turn away from the time-consuming pedagogical task of explaining and debating agonism with deliberative theorists.

\section{The table we sit at - a concluding call}

As mentioned in the introduction, I see two reasons why agonists should stop discussing with deliberative theorists. The first is that the agonism-deliberation discussion has reached an unproductive stalemate, which perhaps relates to the underlying ontological differences between the two theoretical traditions. What is clear is that agonistic theory development in educational research is at the losing end of this stalemate situation. The second reason is that agonists do not need the discussion with deliberative theorists to further develop agonism as an educational theory. Agonism, with its rich theoretical history, constitutes a sufficient theoretical milieu for developing agonism as an educational theory. Given this, I want the essay to be a call to other agonists in educational research that it is time to open up a common symbolic space between us.

But what would characterise such a common symbolic space? Drawing on Mouffe's (2000) notion of this concept (p. 13), it would be a common symbolic space in the sense that it is focused on a shared task to further develop and explore agonism as an educational theory. Even if such a space always contained differences and conflicts, they would revolve around the common task of further developing and exploring agonism. This means that 
the common symbolic space would both relate and separate us as agonists, just as a table relates and separates those who sit around it, to borrow a metaphor from Arendt (1958, p. 52).

At present it is difficult to determine whether agonists share any common symbolic space in educational research. There is, for example, no shared space where the different lines of agonistic thought can confront each other or clash. It would appear that we are sitting at the wrong table and have been doing so for a long time. Therefore, I think that the time has come for us to find another place to sit at.

\section{Acknowledgements}

I would like to dedicate this essay to the memory of Professor Carsten Ljunggren, who was my supervisor, colleague and friend. He provided me with inspiring and thought-provoking comments on an early draft of this essay.

I would like to thank Maria Rosén at Uppsala University for her valuable and helpful comments on this essay. I would also like to thank the two anonymous reviewers for their valuable comments and suggestions. 


\section{References}

Abizadeh, A. (2005) Does Collective Identity Presuppose an Other? On the Alleged Incoherence of Global Solidarity. The American Political Science Review, 99(1), 45-60.

Arendt, H. (1958). The Human Condition. Chicago: The University of Chicago Press.

Bergdahl, L. (2010). Seeing Otherwise. Renegotiating Religion and Democracy as Questions for Education. (Doctoral thesis, Department of Education, 168). Stockholm: Stockholm University.

Connolly, W. E. (1993). The Terms of Political Discourse. Oxford: Blackwell.

Dewey, J. (1927). The Public and Its Problems. Athens: Swallow Press, Ohio State University Press.

Englund, T. (2016). On Moral Education Through Deliberative Communication. Journal of Curriculum Studies, 48(1), 58-76.

Erman, E. (2009). What is Wrong with Agonistic Pluralism?

Reflections on Conflict in Democratic Theory. Philosophy and Social Criticism, 35(9), 1039-1062.

Glover, R. W. (2012). Games without Frontiers? Democratic Engagement, Agonistic Pluralism and the Question of Exclusion. Philosophy and Social Criticism, 38(1), 81-104. Honig, B. (1993). Political Theory and the Displacement of Politics. Ithaca: Cornell University Press.

Koutsouris, G.; Stentiford, L.; Benham-Clarke, S. \& Hall, D. (2021). Agonism in Education: A Systematic Scoping Review and Discussion of its Educational Potential. Educational Review, doi: 10.1080/00131911.2021.1889983

Laclau, E. (2007). On Populist Reason. London: Verso.

Laclau, E. \& Mouffe, C. (2001). Hegemony and Socialist Strategy. Towards a Radical Democratic Politics. London: Verso.

Leiviskä, A. \& Pyy, I. (2020). The Unproductiveness of Political Conflict in Education: A Nussbaumian Alternative to Agonistic Citizenship Education. Journal of Philosophy of Education. doi:10.1111/1467-9752.12512

Ljunggren, C. (1996). Medborgarpubliken och det offentliga rummet. Om utbildning, medier och demokrati [The Citizenpublic and the Public Sphere. On Education, Media and 
Democracy] (Doctoral thesis, Uppsala Studies in Education 68). Uppsala: Acta Universitatis.

Ljunggren, C. (1999a). Questions on Identity and Education. Democracy Between Past and Future (47-60). In C.A. Säfström (Ed.) Identity. Lund: Studentlitteratur.

Ljunggren, C. (1999b). Identitet som konstitutivt handlande [Identity as Constitutive Action]. Utbildning \& Demokrati, 8(1), 63-87.

Ljunggren, C. (2007). Utbildning som politisk kommunikationom deliberation och agonism. [Education as political communication-on deliberation and agonism]. In T. Englund (Ed.), Utbildning som kommunikation. Deliberativa samtal som möjlighet. [Education as communication.

Deliberative communication as a possibility] (205-239). Gothenburg, SE: Daidalos.

Ljunggren, C. (2010). Agonistic Recognition in Education: On Arendt's Qualification of Political and Moral Meaning. Studies in Philosophy and Education, 29(1), 19-33.

Marder, M. (2010). Groundless Existence: The Political Ontology of Carl Schmitt. New York: Continuum.

Mouffe, C. (1999a). Carl Schmitt and the Paradox of Liberal Democracy. In C. Mouffe (Ed.), The Challenge of Carl Schmitt (38-52). London: Verso.

Mouffe, C. (1999b). Deliberative Democracy or Agonistic

Pluralism? Social Research, 66(3), 745-758.

Mouffe, C. (2000). The Democratic Paradox. London, UK: Verso. Mouffe, C. (2005). On the Political. London, UK: Verso.

Pitkin, H. F. (1998). The Attack of the Blob: Hannah Arendt's concept of the social. Chicago: The University of Chicago Press.

Sandel, M. (2006). Public Philosophy: Essays on Morality in Politics. Harvard, MA: Harvard University Press.

Samuelsson, M. (2018). Education for Deliberative Democracy and the Aim of Consensus. Democracy \& Education, 26(1), Article 2.

Schaap, A. (2007). Political Theory and the Agony of Politics. Political Studies Review, 5(1), 56-74.

Schmitt, C. (1932/2007). The concept of the political. Chicago: University of Chicago Press. 
Tryggvason, Á. (2017). The Political as Presence: On Agonism in Citizenship Education. Philosophical Inquiry in Education, 24(3), 252-265.

Tryggvason, Á. (2018a). Democratic Education and Agonism.

Exploring the Critique from Deliberative Theory. Democracy

\& Education, 26(1), Article 1.

Tryggvason, Á. (2018b). Om det politiska i samhällskunskap.

Agonism, populism och didaktik [On the Political in Social

Science Education. Agonism, Populism and Didactics]

(Doctoral thesis, Örebro Studies in Education 58 and

Örebro Studies in Educational Sciences with an Emphasis

on Didactics 17). Örebro: Örebro universitet.

Tryggvason, Á. (2019). How to End a Discussion: Consensus or

Hegemony? Democracy \& Education, 27(2), Article 5.

Zembylas, M. (2018). Political Emotions in the Classroom. How

Affective Citizenship Education Illuminates the Debate

Between Agonists and Deliberators. Democracy \&

Education, 26(1), Article 6.

Ásgeir Tryggvason has a PhD in Education and is a senior lecturer at Örebro University, Sweden. His research focuses on "the political" in education. He has written about agonism and populism in citizenship education and is currently exploring questions about "the political" in relation to environmental and sustainability education.

The terms and conditions of use are related to Creative Commons Attribution Licence (CC-BY) @ (1) 